\title{
Reducing Aviation's Environmental Impact Through Large Aircraft For Short Ranges
}

\author{
Gaetan K.W Kenway* Ryan Henderson† Jason E. Hicken‡ Nimeesha B. Kuntawala ${ }^{\dagger}$, \\ David W. Zingg§ ${ }^{\S}$ \\ Institute for Aerospace Studies, University of Toronto, Toronto, Ontario, M3H 5T6, Canada \\ Joaquim R. R. A. Martins \\ Department of Aerospace Engineering, University of Michigan, Ann Arbor, MI, 48109, USA \\ Ross G. McKeand" \\ Airbus S.A.S, Toulouse, France
}

\begin{abstract}
More than $90 \%$ of high-traffic scheduled flights are less than 1,500 nautical miles; however, the majority of aircraft used on these routes have design ranges considerably longer than $1,500 \mathrm{~nm}$. We show that the impact of civil aviation on climate change can be reduced by using large aircraft designed specifically for the majority of flights — Large Aircraft for Short Ranges (LASR). The reduction in greenhouse gas emissions per passenger kilometer achieved by LASR aircraft is approximately $5 \%$ with respect to narrow body aircraft and $13 \%$ with respect to wide body aircraft. The LASR approach achieves this by a reduction in the operational empty weight afforded by a reduction in the maximum take-off weight. Since this approach does not require novel technology, it can be implemented immediately, yet remains complementary with future technological innovations.
\end{abstract}

\section{Introduction}

The possibility that human actions can warm the planet was debated throughout much of the twentieth century. ${ }^{1}$ However, the mounting evidence for anthropogenic climate change is compelling; the international scientific consensus is that humanity is very likely $(90-99 \%)$ causing global warming. ${ }^{2}$ Climate change demands immediate action, and the airline industry is not exempt. While aviation contributes only $2 \%$ to the total anthropogenic carbon dioxide $\left(\mathrm{CO}_{2}\right)$ emissions, carbon dioxide emissions alone are misleading and do not represent the total radiative forcing from aviation, which is closer to $5 \% .^{3}$

Many technological and operational advances have been proposed to decrease aviation's impact on climate change. Examples include alternative fuels, ${ }^{4,5}$ blended-wing-body configurations,${ }^{6}$ and active-flow control. ${ }^{7,8}$ Each of these ideas has merit and should be investigated. However, they cannot be easily implemented in the short term.

More than $90 \%$ of high-traffic routes flown by airlines are less than 1,500 nm. This represents a significant proportion of aviation's greenhouse gas emissions, so it makes sense to target the efficiency of aircraft used on these short routes.

\footnotetext{
*PhD Candidate, AIAA Student Member

${ }^{\dagger}$ Masters Candidate

${ }^{\ddagger}$ Post-doctoral Researcher, AIAA Student Member

$\S$ Professor and Director, Tier 1 Canada Research Chair in Computational Aerodynamics, J. Armand Bombardier Foundation Chair in Aerospace Flight, Associate Fellow AIAA

"Associate Professor, AIAA Senior Member, "Status Only" Associate Professor, University of Toronto

"Short Range Programme Manager - Product Policy, Strategy and Future Programmes
} 
Using today's technology, a potential solution is Large Aircraft for Short Ranges (LASR). By designing aircraft for short ranges, a lower operational empty weight is realized. This, in turn, increases fuel efficiency and provides a simple yet effective means of reducing aircraft emissions. The objective of this paper is to demonstrate the merit of this approach. An aircraft conceptual design tool is used to determine the performance of a large, short-range aircraft and compare it with existing aircraft on the basis of performance, economics, and environmental impact.

\section{Market Analysis}

The goal of this section is to establish how many existing flights can be replaced by LASRs and to determine the overall market size for LASR aircraft, assuming LASRs will carry approximately 300 passengers in a two-class configuration.

The first step is to identify the airline sector to be targeted by LASRs. In order to limit our analysis to busy routes served by jet aircraft, two assumptions are made about the flight operations of LASRs:

Passenger Traffic: Only one-way, single-stage flights with passenger demand of at least 600 seats per day are considered

Minimum Aircraft Capacity: Only routes where the average aircraft size is at least 100 seats are considered.

The LASR approach is two-fold: first, combine two or more flights of smaller aircraft into a single LASR flight; second, replace the operation of traditional long-range aircraft operating on short, high-density routes with LASRs.

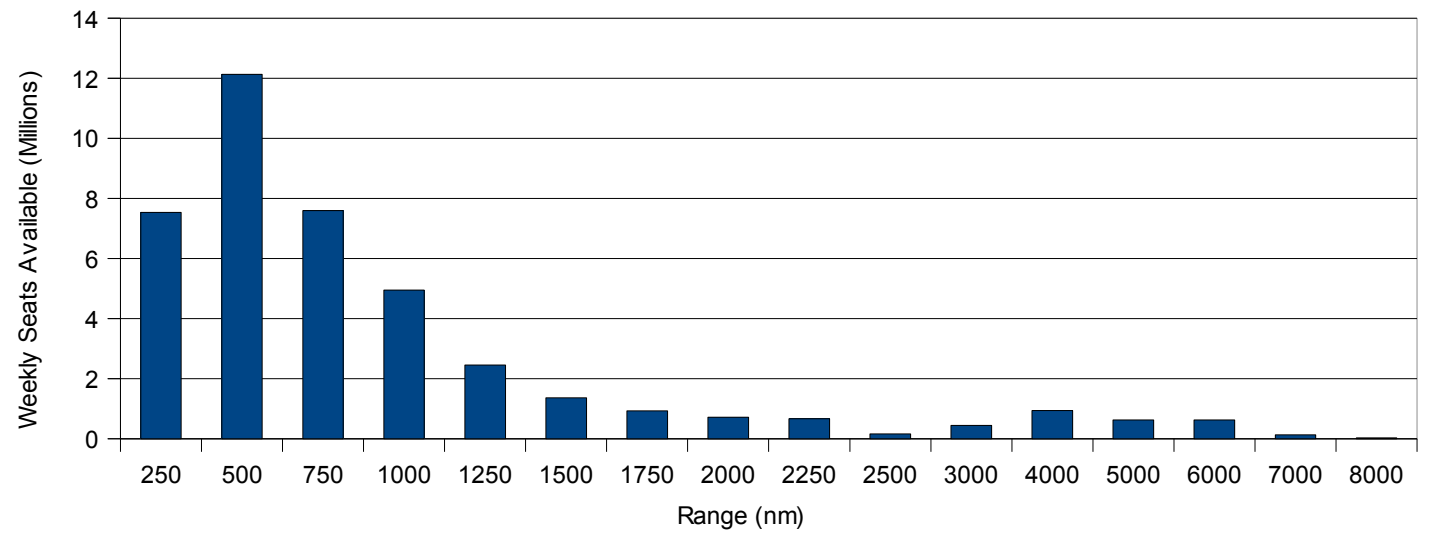

Figure 1. Distribution of flights by length

Using the services of OAG, ${ }^{9}$ all scheduled flights (worldwide, February, 2009) satisfying the above criteria were determined and are shown in Figure 1. The figure provides a picture of the stage length distribution for heavily travelled routes. The vast majority of flights (greater than 90\%) occur at ranges under 1,500 nm; hence this will be used as our target design range. By summing the above chart up to 1,500 nm, we find there are approximately 41 million seats per week available. This can be used to gauge the total size of the market segment for LASRs.

\section{Preliminary Assessment}

The LASR aircraft concept is an example of a reduced range design. A related idea, multi-staging long haul flights, has been discussed by Green. ${ }^{10}$ The later concept is to break long flights into multiple stages, refueling at each stopover. This leads to significantly reduced take-off weight, and a lower total fuel burn. Since the results were first published, a correction addressing the omission of the reserve fuel requirement has been made. ${ }^{11}$ The fundamental fuel saving mechanism is the same in both concepts: a reduction of aircraft operating empty weight achieved by a reduced maximum take-off weight requirement leading to 
lower induced drag and hence fuel burn. Since the LASR concept is related to the reduced-range multistage aircraft design, a preliminary assessment of the LASR concept is conducted using the techniques used by Green as well as other authors (Nangia, ${ }^{12}$ Hahn, ${ }^{13}$ and Creemers ${ }^{14}$ ). All of the above authors use the Breguet range equation for a jet aircraft in a cruise-climb profile:

$$
R=\frac{V}{c} \frac{L}{D} \ln \left(\frac{W_{1}}{W_{2}}\right)=X \ln \left(\frac{W_{1}}{W_{2}}\right)
$$

The parameter $X$ is a combination of the aerodynamic efficiency $\left(\frac{L}{D}\right)$ and the overall propulsive efficiency $\frac{V}{c}$, where $V$ is the flight speed and $c$ is the thrust specific fuel consumption. In broad sense, this can be thought of as a given technology level, with better aerodynamic efficiency and higher efficiency engines pushing $X$ to higher values. $W_{1}$ and $W_{2}$ refer to the weight at the beginning and end of cruise respectively. For Green's analysis, a constant value of $X=30,580 \mathrm{~km}$ is assumed. The simple structural model from Küchemann ${ }^{15}$ is used in Green's analysis:

$$
W_{T O}=c_{1} W_{T O}+c_{2} W_{P}+W_{M F}
$$

where $W_{T O}$ is the take-off weight, $c_{1}$ is a structural weight constant which represents the structural mass that varies with take-off weight, $W_{P}$ is the payload weight, $c_{2}$ is the weight constant that determines the weight of the airframe that varies with payload weight, and finally $W_{M F}$ is the mission fuel burned. We must also account for the reserve fuel, $W_{R F}$, and will express the operating empty weight $(O E W)$ as

$$
O E W+W_{R F}=W_{T O}-W_{M F}-W_{P}=c_{1} W_{T O}+\left(c_{2}-1\right) W_{P}
$$

A $4.5 \%$ approximation for the reserve fuel is used as discussed in Creemers. ${ }^{14}$

The concept of "lost fuel" refers to the fuel burned to accelerate the aircraft to cruise speed, climb to altitude and descend. A value of $2.2 \%$ of take-off weight ${ }^{8}$ is assumed. From the Breguet range equation, the fuel burned during cruise is:

$$
W_{C F}=W_{1}-W_{2}=W_{1}\left(1-e^{\frac{-R}{X}}\right)
$$

and thus the mission fuel is

$$
W_{M F}=W_{C F}+0.022 W_{T O}=W_{T O}\left(1-0.978 e^{\frac{-R}{X}}\right)
$$

A simple iterative scheme is utilized to find a consistent solution for $O E W, W_{M F}$ and $W_{T O}$ based on the following equations:

$$
\begin{aligned}
W_{M F} & =W_{T O}\left(1-0.978 e^{\frac{-R}{X}}\right) \\
W_{R F} & =0.045 W_{T O} \\
O E W & =\left(c_{1}-0.045\right) W_{T O}+\frac{\left(c_{2}-1\right) W_{T O}\left(0.978 e^{\frac{-R}{X}}-c 1\right)}{c_{2}} \\
W_{T O} & =O E W+W_{M F}+W_{R F}+W_{P}
\end{aligned}
$$

Using the structural weight constant values of $c_{1}=0.351$ and $c_{2}=2.6$ as suggested by Green, ${ }^{8}$ we obtain the results in Table 1 In contrast to Green, we keep the value of $c_{2}$ fixed, as changing its value would erroneously result in a decrease of the structural mass related to the fixed passenger payload of 293 people. We must ensure the fuselage and furnishings mass are identical between both aircraft to ensure the same capacity.

The first observation we can make is that splitting up a 6,400 $\mathrm{nm}$ journey into approximately four $1,500 \mathrm{~nm}$ legs with the same aircraft does not result in a substantial fuel savings. This implies that the fuel savings derived from multi-stage long range travel only occur on much longer routes or through aircraft redesign for the shorter range. The second observation is that for a redesigned LASR aircraft, the OEW has decreased by approximately $26 \%$ with a corresponding $22 \%$ reduction in fuel burn. Based on this preliminary analysis, it appears that the LASR concept warrants further investigation. 
Table 1. Simple LASR aircraft analysis

\begin{tabular}{|c|c|c|c|c|c|c|c|c|c|c|c|}
\hline Description & $c_{1}$ & $c_{2}$ & $\begin{array}{l}\text { Range } \\
(\mathrm{nm})\end{array}$ & $\begin{array}{l}\text { Payloa } \\
\text { (tonne }\end{array}$ & $\begin{array}{l}\text { dFuel } \\
\text { (tonne }\end{array}$ & $\begin{array}{l}\text { Reser } \\
\text { (tonne }\end{array}$ & $\begin{array}{l}\text { veTOW } \\
\text { (tonne) }\end{array}$ & $\begin{array}{l}\text { OEW } \\
\text { (tonne) }\end{array}$ & $\begin{array}{l}\text { Fuel } \\
\text { for } \\
6,400 \\
\text { (tonne }\end{array}$ & $\begin{array}{l}\% \\
\text { OEW } \\
\text { nhange } \\
\end{array}$ & $\begin{array}{l}\% \quad \text { Fuel } \\
\text { Burn } \\
\text { Change }\end{array}$ \\
\hline Airbus A330 & 0.351 & 2.6 & 6,400 & 27.97 & 78.2 & 10.5 & 232.5 & 115.9 & 78.16 & - & - \\
\hline Airbus A330 & 0.351 & 2.6 & 1,500 & 27.97 & 18.1 & 7.6 & 169.6 & 115.9 & 77.4 & $0.00 \%$ & $-1.01 \%$ \\
\hline LASR & 0.351 & 2.6 & 1,500 & 27.97 & 14.4 & 6.0 & 134.1 & 85.8 & 61.18 & $-26.00 \%$ & $-21.76 \%$ \\
\hline
\end{tabular}

\section{Detailed Analysis}

In this section, the details behind the performance analysis of a LASR aircraft in comparison with selected aircraft are provided. The aim is to demonstrate that a large, short-range aircraft can provide significant fuel burn savings per passenger over both an existing aircraft of similar size flying at this shorter range and a current smaller aircraft designed for a range of 3,000 nm.

To investigate the fuel savings of operating a LASR aircraft in lieu of existing aircraft, a conceptual design tool was used. The design tool is based on pyACDT, an object-oriented framework for the design and optimization of aircraft. ${ }^{16}$ This framework uses object-oriented concepts to model the aircraft components, engine components, mission dependent characteristics, and disciplinary analyses to achieve the required scalability and extensibility required for multidisciplinary design. All necessary disciplines required at the conceptual design level are considered, with low to medium fidelity models being used to provide rapid execution and robustness.

The design tool was developed in part for use in multidisciplinary optimization, and as such, has the ability to allow the user to rapidly modify the selection of objective functions, design variables and constraints. Table 2 lists the design variables selected for the optimizations performed in this study.

Table 2. Optimization design variables

Sea-level Static Thrust
Cruise Altitude
Wing Reference Area
Horizontal Stabilizer Area
Vertical Stabilizer Area

The objective is to analyze the baseline aircraft and the LASR aircraft as accurately as possible to make comparisons. We wish to optimize the LASR for a specific range and then compare the LASR's performance to the performance of the reference aircraft at this design range. The Airbus A330-200 was selected as the large, long-range reference aircraft, since its two-class seating capacity is 293 seats, which is very close to our target aircraft size of 300 seats. The Airbus A330 Airplane Characteristics for Airport Planning document ${ }^{17}$ was used to obtain the reference aircraft weight and performance data listed in Table 3 Additionally, we compare the LASR performance with a smaller aircraft, the A320, which is often used on routes relevant to LASR.

The aircraft conceptual design tool is a set of analyses which allow the modelling of aircraft geometry, structural weight breakdown, aerodynamics, propulsion and performance. ${ }^{18}$ The geometry of each aircraft component is derived from a set of primary physical attributes and additional geometric parameters.

The aircraft takeoff weight is calculated iteratively from main component weights that are estimated using statistical methods ${ }^{19-21}$ and from mission fuel requirements. The propulsion system weight includes engine, oil, thrust reverser, starting system and control systems weights, all of which are a function of takeoff thrust. The structural weight group includes wing, empennage, landing gear, fuselage and nacelle weights. Empennage weight is calculated from correlations based on maximum takeoff weight, lifting surface planform geometry and airfoil thicknesses. The nacelle weight is proportional to the engine geometrical size and the maximum takeoff thrust. The fuselage weight is solely based on its overall geometry, and the landing gear

$$
4 \text { of } 11
$$


Table 3. Baseline configurations

\begin{tabular}{lrr}
\hline & A330-200 & A320 \\
\hline \hline Design Range (nm) & 6,400 & 3,000 \\
Passengers (2-class) & 293 & 150 \\
MTOW (kg) & 233,000 & 77,000 \\
OEW (kg) & 116,740 & 41,345 \\
Engine & CF6-80E1 & CFM56-5B5 \\
Payload Weight (kg) & 27,215 & 14,288
\end{tabular}

weight is correlated to the aircraft maximum takeoff weight. Finally, the wing and control surface weights are proportional to an ultimate load factor, the wing planform geometry and the takeoff gross weight. ${ }^{22}$ The furnishings-group weights include elements such as seats, lavatories, windows, emergency systems and galleys. Operational items that are considered in this analysis include attendants and crew weights, unusable fuel weight and other operational items typical in commercial aircraft. The systems group weight is the summation of individual weights for systems such as anti-ice, avionics, air-conditioning, electrical, APU, fuel, hydraulic, flight control and instrumentation. Finally, the payload weight includes passenger and baggage weights, as well as any other cargo carried during flight. Table 4 lists all the major weight groups considered and the factors that influence the weight of each component in that group.

Aircraft lift and drag are calculated based on standard aerodynamic calculations used at the conceptual design stage. Induced, parasite, and wave drag calculations are considered. The induced drag is calculated using a panel method whereas parasite drag is calculated using a detailed component build-up. The propulsion module is a cycle analysis code used to model the engine at its design point and at all off-design conditions, including any combination of Mach number, altitude, and throttle setting. The performance model provides point performance calculations over a specified mission profile. Takeoff and landing distances, rates of climb, and range are calculated based on analytical expressions or numerical simulations.

To estimate the fuel consumed over an entire flight, the fuel burn of multiple segments are modelled using take-off weight (TOW) fuel fractions. This permits rapid estimations of fuel burn on secondary segments while taking into account the benefits of a lower TOW. The fuel usage during climb is estimated as a function of weight as well as final climb altitude. Finally, the reserve fuel is simply a small fraction of the aircraft MTOW.

With the above assumptions on fuel consumption, general aircraft geometry characteristics and engine cycle parameters, the A330-200 aircraft, in a 293 passenger 2-class configuration with two CF6-80E1 engines, was modelled with the design tool.

To make comparisons as accurate as possible, minor adjustments were made to the analysis to match its performance as closely as possible to the data in Table 3. Since detailed aerodynamic, propulsion and weight data is unavailable, it is difficult to predict specific sources of error. However, two modifications were implemented to ensure the model more closely matches published data. The first modification is adding a $5 \%$ weight increment to all structural components in the aircraft. The second modification is a $5 \%$ decrease in the aircraft thrust specific fuel consumption (SFC). Since all aircraft designed or optimized in this framework share the same engine cycle parameters, the slight tuning of the SFC will affect all in the same fashion. It is also quite difficult to correct this error without detailed information regarding engine component efficiencies and cycle parameters. Having applied these two modifications, the performance and weight data for the A330-200 and A320 are listed in Table 5 and are comparable to published data, thus supporting the accuracy of our model.

Simulations were run to estimate the fuel burn of these aircraft at ranges other then their design range. The initial cruise altitude was selected parametrically by optimizing for minimum mission fuel consumption. The selection was a balance between cruise-efficiency and climb-fuel requirements, while ensuring that the aircraft had an adequate maximum thrust-to-drag ratio at that altitude.

The framework was then used to redesign and optimize aircraft with the same capacity for the shorter ranges. The cruise Mach number was kept constant at 0.78 to ensure that all aircraft under comparison would maintain similar block times. Constraints were also imposed on the optimized aircraft, including 
Table 4. Components considered in weights and c.g. module

\begin{tabular}{|c|c|c|}
\hline Weight Group & Component & Dependencies \\
\hline Structural & $\begin{array}{l}\text { Wing } \\
\text { Horizontal Tail } \\
\text { Vertical Tail } \\
\text { Nacelle } \\
\text { Fuselage } \\
\text { Landing Gear }\end{array}$ & $\begin{array}{l}\text { Geometry, Load Factor, MTOW } \\
\text { Geometry, MTOW } \\
\text { Geometry, MTOW } \\
\text { Geometry, MTOT }{ }^{b} \\
\text { Geometry } \\
\text { MTOW }\end{array}$ \\
\hline Propulsion & $\begin{array}{l}\text { Engine } \\
\text { Oil } \\
\text { Thrust Reverser } \\
\text { Starting System } \\
\text { Control System }\end{array}$ & $\begin{array}{l}\text { MTOT } \\
\text { MTOT } \\
\text { MTOT } \\
\text { EW nEngd } \\
\text { MTOT }\end{array}$ \\
\hline Systems & $\begin{array}{l}\text { Anti-ice } \\
\text { Avionics } \\
\text { Air-conditioning } \\
\text { APU } \\
\text { Electrical } \\
\text { Fuel System } \\
\text { Hydraulics } \\
\text { Flight Control } \\
\text { Instruments }\end{array}$ & $\begin{array}{l}\text { Wing, Nacelle, Fuselage Geometry } \\
\text { MTOW } \\
\text { Fuselage Volume, nCrew }{ }^{e} \text { nAttd }{ }^{f} \text { nax } g \\
\text { Fuselage Geometry, nCrew, nAttd, nPax } \\
\text { Fuselage Geometry, nEng, nCrew, nPax } \\
\text { nEng, Fuel Volume, nTanks } \\
\text { nEng, CSA } \\
\text { CSA } \\
\text { nCrew, MTOW, MTOT }\end{array}$ \\
\hline Furnishings & $\begin{array}{l}\text { Seats } \\
\text { Lavatories } \\
\text { Galleys } \\
\text { Emergency Systems } \\
\text { Windows }\end{array}$ & $\begin{array}{l}\text { nCrew, nAttd, nPax } \\
\text { nPax } \\
\text { nPax } \\
\text { nCrew, nAttd, nPax, MTOW } \\
\text { nPax }\end{array}$ \\
\hline Operational & $\begin{array}{l}\text { Attendants } \\
\text { Crew } \\
\text { Unusable Fuel } \\
\text { Cargo }\end{array}$ & $\begin{array}{l}\text { nAttd } \\
\text { nCrew } \\
\text { Wing Area, MTOT, nTanks, FW }{ }^{j} \\
\text { Baggage and Cargo Weight, nCont }\end{array}$ \\
\hline Payload & $\begin{array}{l}\text { Passengers } \\
\text { Baggage, nPax }\end{array}$ & nPax \\
\hline Fuel & Fuel Weight & MTOW, Mission \\
\hline
\end{tabular}

${ }^{a}$ MTOW - Maximum Takeoff Weight

${ }^{b}$ MTOT - Maximum Takeoff Thrust

${ }^{c} \mathrm{EW}$ - Engine Weight

${ }^{d}$ nEng - Number of Engines

${ }^{e}$ nCrew - Number of Crew

$f_{\text {nAttd }}$ - Number of Attendants

${ }^{g} \mathrm{nPax}$ - Number of Passengers

$h_{\text {nTanks - Number of Fuel Tanks }}$

${ }^{i} \mathrm{CSA}$ - Control Surface Areas

${ }^{j} \mathrm{FW}$ - Fuel Weight

${ }^{k}$ nCont - Number of Cargo Containers 
Table 5. Accuracy of reference model

\begin{tabular}{l|rr|rr}
\hline Variable Name & Actual Data & A330-200 & Actual Data & A320 \\
\hline \hline MTOW (kg) & 233,000 & 232,888 & 75,499 & 76,567 \\
OEW (kg) & 116,739 & 115,951 & 41,243 & 42,114 \\
FW (kg) & 88,166 & 88,814 & 19,967 & 20,135 \\
Payload (kg) & 28,123 & 28,123 & 14,288 & 14,288
\end{tabular}

takeoff field length, second-segment engine-out climb gradient and cruise maximum thrust-to-drag ratio. Table 6 indicates performance, weight, and aerodynamic data for the two reference aircraft, and the optimized aircraft for flights of 1,500 nm, 1,000 nm and $500 \mathrm{~nm}$. Planform views of the A330 and the LASR are shown in Figure 2 .

From the table, we find that on a flight of $1,500 \mathrm{~nm}$, the LASR can offer up to $13 \%$ reduction in fuel burn per passenger in comparison to the A330-200 and 5\% compared to the A320. The savings relative to the A330-200 are even larger at the shorter ranges.
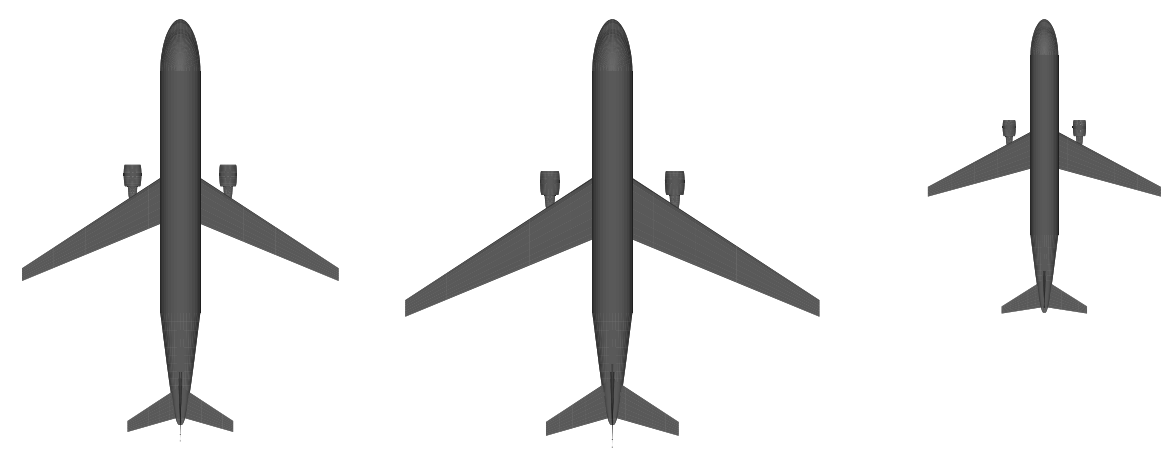

Figure 2. Planform view of LASR (left), A330 (center) and A320 (right)

\section{Economic Analysis}

Economic justification of a new aircraft such as the LASR is vital to its adoption by the airline industry. The following analysis considers the economic performance of the LASR in comparison with the Airbus A320 and A330-200.

Table 7 provides a per-trip breakdown of total cash operating cost (COC) for a LASR in comparison with two A320's (to provide a 300 seat cpacity compared to the 293 seat capacity LASR) and one A330-200 over a range of 1,500 $\mathrm{nm}$. The 'Change Per Seat' column represents the change in cost presented by the LASR on a per seat basis relative to the two A320's and the A330-200, respectively. From this table, we can see that the LASR provides significant cost savings over these aircraft; the most significant savings are from fuel costs: the LASR reduces this expense by more than $\$ 4$ US and $\$ 8$ US per passenger relative to the two A320's and A330-200, respectively. In the situation where fuel prices increase beyond the assumed $\$ 3$ US/gallon, the potential savings presented by the LASR are obvious. The second most significant savings over the two alternatives are those from the Navigation, Landing and Handling fees. These savings come mainly from the MTOW-savings presented by the LASR since both Navigation and Landing fees are assumed to depend on this value. Given that landing fees can also include carbon taxes and the fuel burn savings presented by the LASR, the advantage the LASR has over these aircraft can only increase. Overall, one LASR results in almost $12 \%$ per trip savings over two A320's and almost $13 \%$ per trip savings over one A330-200. On a COC per seat basis, the LASR presents savings of roughly $9 \%$ and $13 \%$ relative to the A320 and A330-200, respectively. 
Table 6. Performance analysis results

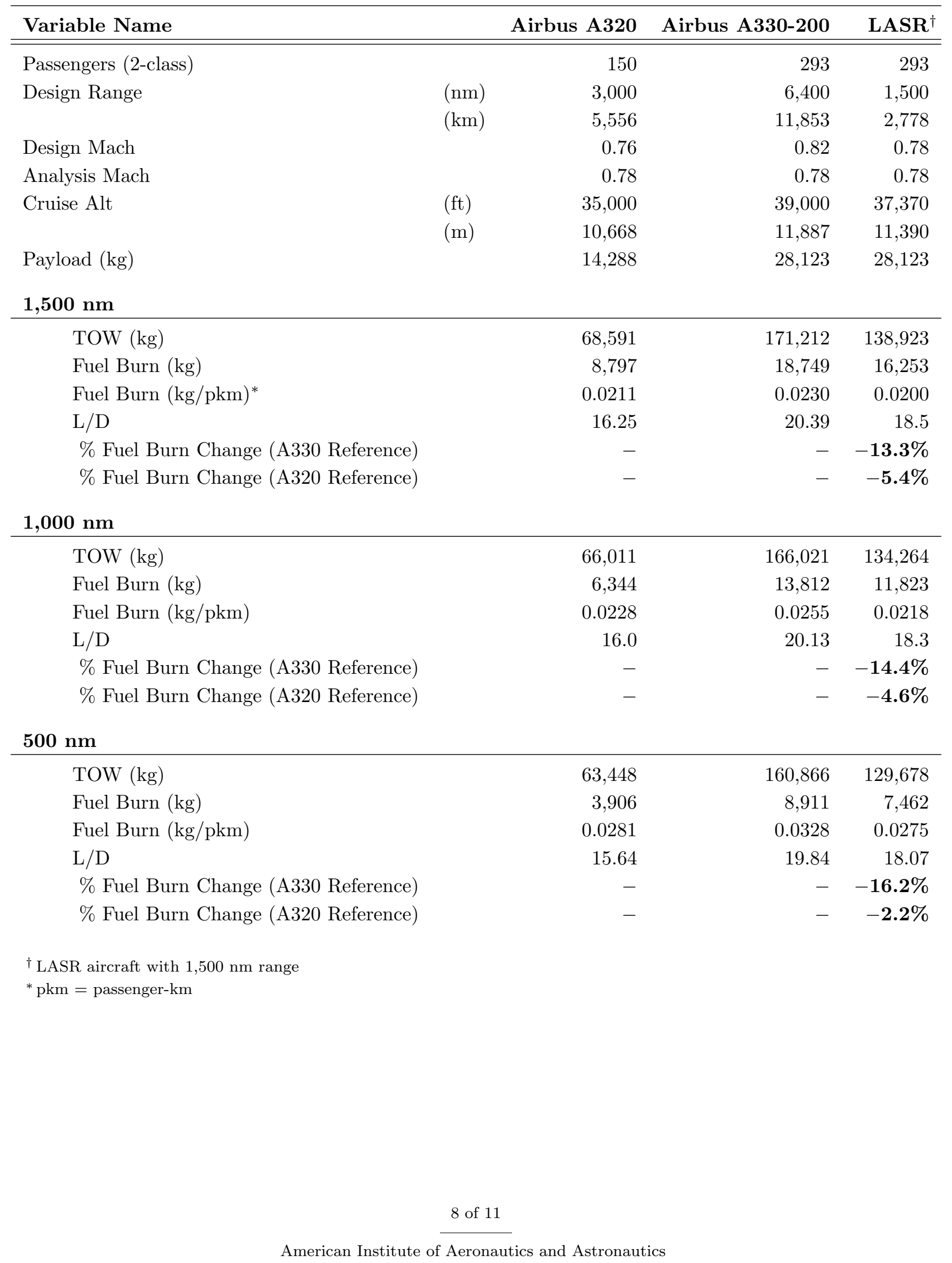


Table 7. Total per trip Cash Operating Cost (COC) breakdown in USD for range of $1,500 \mathrm{~nm}$

\begin{tabular}{lr|r|r|rr} 
& Two A320s & A330-200 & \multicolumn{3}{|c}{ LASR } \\
\cline { 2 - 6 } & & & & \multicolumn{2}{c}{ Change Per Seat w.r.t. } \\
& Cost & Cost & Cost & Two A320s & A330 \\
\hline \hline Fuel (\$3 US/gallon) & 17,354 & 18,493 & 16,031 & $-\$ 4.41$ & $-\$ 8.40$ \\
Maintenance & 2,275 & 2,275 & 1,970 & $-\$ 1.02$ & $-\$ 1.04$ \\
Flight Crew & 2,800 & 1,750 & 1,663 & $-\$ 3.79$ & $-\$ 0.30$ \\
Cabin Crew & 1,400 & 1,260 & 1,260 & $-\$ 0.47$ & $\$ 0.00$ \\
Catering, Reservation and Lounge & 3,420 & 3,537 & 3,537 & $+\$ 0.39$ & $\$ 0.00$ \\
Navigation, Landing and Handling & 7,791 & 8,192 & 6,532 & $-\$ 4.20$ & $-\$ 5.67$ \\
\hline Total Cash Operating Costs & 35,040 & 35,506 & 30,993 & $-\$ 13.49$ & $-\$ 15.40$ \\
\% Change per seat & & & & $\mathbf{- 9 . 4 3 \%}$ & $\mathbf{- 1 2 . 7 \%}$
\end{tabular}

\section{Environmental Analysis}

In this section, we consider the environmental impact of LASR using the total emissions per passenger on a $1,500 \mathrm{~nm}$ flight.

What is the environmental impact of a 300 passenger aircraft during a 1,500 nm flight? This is a difficult question, but, if we want to compare aircraft, an approximate answer is given by the total mass of greenhouse gases (GHG's) emitted during the flight. Emissions of a particular GHG are estimated using the following equation:

$$
E_{i}=e_{i} W_{\text {fuel }},
$$

where $E_{i}$ is the mass of species $i$ emitted, $e_{i}$ is the emissions index for species $i$, and $W_{\text {fuel }}$ is the mass of fuel burned. The greenhouse gas species considered are carbon dioxide $\left(\mathrm{CO}_{2}\right)$, water $\left(\mathrm{H}_{2} \mathrm{O}\right)$, sulfate, soot, and nitrogen oxide $\left(\mathrm{NO}_{x}\right)$. The emissions indices for these species are listed in Table 8 . Note, the emission index for nitrogen oxide varies with altitude, Mach number, and fuel-flow rate. We use the DLR fuel-flow-correlation model (see Ref. 23, for example) to estimate the emission index for nitrogen oxide.

Table 8. Emissions indices for various greenhouse gas species

\begin{tabular}{cccccc}
\hline & $\mathbf{C O}_{2}$ & $\mathbf{H}_{2} \mathbf{O}$ & sulfate & soot & NO $_{x}$ \\
\hline \hline$e_{i}(\mathrm{~g} / \mathrm{kg})$ & 3,160 & 1,230 & 0.2 & 0.04 & $0.013-0.017$
\end{tabular}

We compare the GHG emissions of an A330-200, an A320, and a LASR over a 1,500 nm flight. The LASR aircraft has been optimized for the chosen range, but all three aircraft use similar technology. For example, we assume the LASR and A330-200 are equipped with two General Electric CF6-80E1A2 engines, while the A320 is equipped with two CFM56-5B5 engines. The necessary engine emission data is obtained from the ICAO databank. ${ }^{24}$

Table 9 lists the GHG (kg per passenger) for the three aircraft on a 1,500 $\mathrm{nm}$ flight. On a per passenger basis, the LASR reduces $\mathrm{CO}_{2}, \mathrm{H}_{2} \mathrm{O}$, sulfate, and soot emissions by $13.3 \%$ relative to the A330-200, and $5.4 \%$ relative to the A320. These are significant improvements considering that no new technology is required. In terms of nitrogen oxide emissions, the LASR produces $28 \%$ less $\mathrm{NO}_{x}$ than the A330-200, and has similar emissions to the A320.

\section{Conclusions and Recommendations}

We have shown that large aircraft designed for short ranges can reduce the environmental impact of aviation while offering economic advantages. On a 1,500 nm flight, a LASR aircraft designed for 1,500 nm 
Table 9. Comparison of emissions per passenger for the A320, A330-200, and LASR over a 1,500 nm flight

\begin{tabular}{lrrr}
\hline & A320 & A330-200 & LASR \\
\hline \hline passengers & 150 & 293 & 293 \\
fuel burned (kg) & 8,797 & 18,749 & 16,253 \\
& & & \\
emissions (kg/pass.) & & & \\
\hline $\mathrm{CO}_{2}$ & 185 & 202 & 175 \\
$\mathrm{H}_{2} \mathrm{O}$ & 72.1 & 78.7 & 68.2 \\
sulfate & 0.0117 & 0.0128 & 0.0111 \\
soot & 0.00235 & 0.00256 & 0.00222 \\
& & & \\
$\mathrm{NO}_{x}$ & 0.785 & 1.08 & 0.776
\end{tabular}

reduces $\mathrm{CO}_{2}$ emissions per passenger by $5.4 \%$ and $13 \%$ relative to an A320 and an A330-200, respectively. The LASR concept improves aircraft efficiency using existing technologies, so it can be implemented quickly to help mitigate aviation's climate impact. Moreover, the concept is not tied to a specific technology, so its advantages will extend to future technologies and operations, including blended-wing bodies, active flow control, all-composite structures, continuous-descent landing, and multi-stage long-range flights.

In order to achieve these benefits, the following disadvantages must be accepted. The first is the reduction in flight frequency on busy routes, which restricts an airline's ability to compete with more frequent flights on other airlines. The second is the burden placed on airlines to manage a less flexible fleet of aircraft. A short continental flight followed by a long-haul inter-continental flight is no longer possible with the same aircraft. Overall, however, we believe the benefits of reduced cost and emissions are sufficient to outweigh these disadvantages.

\section{References}

${ }^{1}$ Weart, S. R., The Discovery of Global Warming, Harvard University Press, Cambridge, Massachusetts, 2003.

2 "Climate Change 2007: IPCC Synthesis Report," Tech. rep., Valencia, Spain, Nov. 2007, http://www.ipcc.ch/index.htm.

3 "Aviation and the Global Atmosphere," Tech. rep., 1999, http://www.ipcc.ch/ipccreports/special-reports.htm.

${ }^{4}$ Bogers, P., "The role of alternative fuels in air transport - options and challenges," UTIAS-MITACS International Workshop on Aviation and Climate Change, Toronto, Canada, May 2008,

http://goldfinger.utias.utoronto.ca/ĩwacc/program_files/bogers_iwacc_2008.pdf.

${ }^{5}$ Saynor, B., Bauen, A., and Leach, M., "The potential for renewable energy sources in aviation," Tech. rep., Imperial College Centre for Energy Policy and Technology, London, England, Aug. 2003.

${ }^{6}$ Liebeck, R., "Design of the blended wing body subsonic transport," Journal of Aircraft, Vol. 41, No. 1, 2004 , pp. 10-25.

${ }^{7}$ Schrauf, G., "Status and perspectives of laminar flow," The Aeronautical Journal, Dec. 2005, pp. 639-644.

${ }^{8}$ Green, J. E., "Civil aviation and the environment — the next frontier for the aerodynamicist," The Aeronautical Journal, Aug. 2006, pp. 469-486.

${ }^{9}$ Tech. rep., accessed March 2009, http://www. oag.com.

${ }^{10}$ Green, J., "Greener by Design - the technology challenge," The Aeronautical Journal, Feb. 2002.

${ }^{11}$ Green, J., "Küchemanns weight model as applied in the first Greener by Design Technology Sub Group Report: a correction, adaptation and commentary," The Aeronautical Journal, 2006.

${ }^{12}$ Nangia, R., "Efficiency parameters for modern commercial aircraft," The Aeronautical Journal, 2006.

${ }^{13}$ Hahn, A. S., "Staging Airliner Service," 7th AIAA Aviation Technology, Integration and Operations Conference, Belfast, Northern Ireland, 2007.

${ }^{14}$ Creemers, W. and Slingerland, R., "Impact of intermediate stops on long-range jet-transport design," 7th AIAA Aviation Technology, Integration and Operations Conference, Belfast, Northern Ireland, 2007.

${ }^{15}$ Küchemann, D., The Aerodynamic Design of Aircraft, Pergamon Press, 1978.

${ }^{16}$ Perez, R. E. and Martins, J. R. R. A., "pyACDT: An Object-Oriented Framework for Aircraft Design Modelling and Multidisciplinary Optimization," Proceedings of the 12th AIAA/ISSMO Multidisciplinary Analysis and Optimization Conference, Victoria, BC, September 2008. 
${ }^{17}$ Airbus, "A330 Airplane Characteristics for Airport Planning AC," Tech. rep.

${ }^{18}$ Perez, R. E., Henderson, R., and Martins, J. R. R. A., "Multidisciplinary Design Optimization of Airframe and Engine for Emissions Reduction," Proceedings of the 12th AIAA/ISSMO Multidisciplinary Analysis and Optimization Conference, Victoria, BC, September 2008.

${ }^{19}$ Raymer, D., Aircraft Design: A Conceptual Approach, AIAA Education Series, American Institute of Aeronautics and Astronautics, Washington, DC, 3rd ed., 1999.

${ }^{20}$ Torenbeek, E., Synthesis of Subsonic Airplane Design, Delft University Press and Kluwer Academic Publishers, 6th ed., 1990.

${ }^{21}$ Roskam, J., Airplane Design, Vol. 1-8, DARCorporation, Ottawa, KS, 2nd ed., 1998.

${ }^{22}$ Kroo, I., "Aircraft Design: Synthesis and Analysis," 2006, http://adg.stanford.edu/aa241/AircraftDesign.html, cited February, 2009.

${ }^{23}$ Schulte, P., Schlager, H., Ziereis, H., and Schumann, U., "NO$x$ emission indices of subsonic long-range jet aircraft at cruise altitude: In situ measurements and predictions," Journal of Geophysical Research, Vol. 102, 1997, pp. $21431-21442$.

24 "ICAO Engine Emissions Databank," Tech. rep., Montréal, Quebec, Canada, accessed March 2009, http: //www . caa.co.uk/default . aspx? catid=702\&pagetype=90f. 